ORIGINAL ARTICLE

\title{
Morphometric Study on the Energy Drink Induced Pancreatitis on Wistar
} Albino Rats

\author{
Fatima Rehman', Zia-UI-Islam', Sama-ul-Haq', Lubna Faisal', Sadia Rehman³, Santosh Kumar \\ 1. Department of Anatomy, Liaquat National Hospital and Medical College Karachi, Pakistan. \\ 2. Department of Anatomy, Fazaia Ruth Pfau Medical College, Karachi, Pakistan. \\ 3. Department of Biochemistry, Bahria University Medical \& Dental College, Karachi, Pakistan. \\ 4. Department of Nephrology, Jinnah Post Graduate Medical Center Karachi, Pakistan. \\ Correspondence to: Dr. Fatima Rehman, Email: fatimakureshi@hotmail.com, ORCiD: 0000-0002-5264-8939
}

\begin{abstract}
Objective: To assess the effects of energy drinks on the micrometric measurements of pancreas of Wistar Albino rats. Methods: This experimental study was conducted in the Department of Anatomy, in collaboration with the animal house of Basic Medical Sciences Institute (BMSI), Jinnah postgraduate medical center (JPMC), Karachi from September to October 2018. Thirty adult male Wistar Albino rats were equally divided into three groups (Group $A$ as control, while groups B and $C$ were administered $7.5 \mathrm{ml}$ and $15 \mathrm{ml}$ orally for four weeks, respectively). Pancreas was dissected out at the end of study. After tissue processing, slides were made and stained with hematoxylin and eosin stain (H\&E) to observe the morphology and cytoarchitecture of the tissue.

Results: The findings of the study revealed that the mean diameter of pancreatic acini and islets were significantly lower in Group B (12.70 \pm 1.20$),(63.52 \pm 8.98)$ as compared to Group A (26.29 \pm 4.37$),(123.66 \pm 22.08)$ respectively, p-value <0.05. Diameter of pancreatic acini and islets were significantly less in Group C (10.06 \pm 0.89$),(44.58 \pm 7.66)$ as compared to both Groups A (26.29 \pm 4.37), (123.66 \pm 22.08$)$ and Group B (12.70 \pm 1.20$),(63.52 \pm 8.98)$ respectively, p-value <0.01. The parenchyma of the observed organ was also damaged with loss of normal cytoarchitecture as observed on microscopy.

Conclusion: The results obtained in the current study suggest that consumption of energy drinks seriously damages the regular anatomy of the pancreas of Wistar Albino rats.

Keywords: Acini, diameter, energy drink, islets of Langerhan's, parenchyma.
\end{abstract}

This is an Open Access article distributed under the terms of the Creative Commons Attribution Non-Commercial License (http:// creative commons. org/licenses/by-nc/4.0) which permits unrestricted non-commercial use, distribution, and reproduction in any medium, provided the original work is properly cited.

\section{INTRODUCTION}

Energy drinks are the beverage of choice for the younger generation.' A classical type of energy drink has a composition of water, sugar, caffeine in variable quantity, some bioactive compounds like guarana, glucoronolactone, and taurine, different types of vitamin B like niacin, pantothenic acid, and cobalamin. ${ }^{2}$ Caffeine is a commonly consumed phytochemical, utilized both pharmacologically as well as industrially in beverage manufacturing. It is a centrally-acting stimulant affecting the nervous system by antagonizing the adenosine receptors. ${ }^{3}$ It enhances the mental alertness and delays the feeling of fatigability when consumed in an energy drink, which possibly justifies its role in these beverages. ${ }^{4}$

The glucose component in energy-enhancing beverages is usually responsible for providing a substrate required for physiological energy. They are also associated with the effects of the autonomic nervous system. There is strong evidence of a significant increase in both the pulse rate as well as blood pressure following the administration of energy drinks. $^{5}$

Another important ingredient of energy drink is a nonessential sulfur-containing amino acid taurine. It is present in sufficient quantity in a regularly consumed balanced diet. Disturbance in the homeostasis of taurine is found to be associated with potentially hazardous effects on the brain, heart, and skeletal system of the human body. ${ }^{6}$ It can produce cardiac arrhythmias and disturbance in heart rate. The neurological deficits can be as minor as mood swings and behavioral disorders as complex as epilepsy and autism, associated with taurine imbalances in body. ${ }^{7,8}$

Some of the studies have also revealed that the structure and function of the pancreas are likewise disrupted following the intake of caffeinated beverages. It has been observed that the damage affects both the exocrine and endocrine parts of the organ with the functional disturbances as well. ${ }^{9}$ Although very limited data is available at present to show the toxic role of energy drinks on the pancreatic tissue. With the developing trend of consumption of 
caffeinated beverages by the younger generation of today, the untoward effects on different organs of the body need to be identified. The current study was therefore aimed to observe the morphometric changes induced by the consumption of energy drinks on the pancreas of Wistar Albino rats.

\section{METHODS}

This laboratory-based experimental study was conducted in the Department of Anatomy in alliance with the animal house of Basic Medical Sciences Institute (BMSI), Jinnah postgraduate Medical Center, Karachi, from September to October 2018. The ethical approval for the experimentation was sought from the ethical committee of BMSI (Letter No. F.1-2/2018/BMSIE.COMT/069/JPMC dated 28.09.2018).

Thirty adult male Wistar Albino rats, weighing between 250-300 grams were used in the study. The animals were handled following the guidelines provided by the institution. One week before the start of the study, they were kept under observation to assess their health. They were fed on standard laboratory chow and water ad libitum.

All the animals were randomly divided into three groups, each comprising of ten animals. The grouping was done on the following basis

Group A: On standard laboratory diet and water ad libitum, served as control

Group B: Energy drink treated at a dose of $10 \mathrm{mg} / \mathrm{kg}$ equivalent to $7.5 \mathrm{ml} /$ day

Group C: Energy drink treated at a dose of $20 \mathrm{mg} / \mathrm{kg}$ equivalent to $15 \mathrm{ml} /$ day

A commonly available energy drink in Pakistan, packaged in $250 \mathrm{ml}$ cans, was used in the study (the identity of the drink was kept hidden for legal purpose). This drink had a composition of $80 \mathrm{mg}$ of caffeine, 1000 $\mathrm{mg}$ of taurine, and $27 \mathrm{~g}$ of sugar. It was administered via a gastric tube orally at a dose of 7.5 and $15 \mathrm{ml}$ to all the animals of groups $B \& C$ respectively for 30 days. The animals were sacrificed at the end of the completion period and the pancreas was dissected out.

After tissue processing, slides were made and stained with hematoxylin and eosin stain (H\&E) to observe the morphology and cytoarchitecture of the tissue. Each slide was observed under the light microscope at $100 \mathrm{X}$ magnification at four non-overlapping, randomly selected fields. Histological analysis was done to observe the vascular congestion, mononuclear cell infiltration and tissue edema. The diameter of pancreatic acini and islets of Langerhan's were measured by using a built-in software installed in a digitalized board system (DS camera control-DS-L2, Nikon), attached with a light microscope (Nikon Eclipse 50i, Japan). The observations were made at $400 \mathrm{X}$ in micrometers.

Two measurements were taken for each acinus as well as islets each pancreatic section by using the area calibrated ocular grid. Maximum transverse and vertical axes were measured and then the mean was calculated by adding both the transvertical axes divided by 2 , using the following formula:

Average diameter $=$ (maximum transverse axis + maximum vertical axis $) / 2 .^{10}$

Statistical software SPSS version 20 was used for data analysis. The quantitative variables like diameter of pancreatic acini and islet of Langerhans were measured as mean \pm SD. Statistical assessment was performed by using one-way analysis of variance with multiple comparisons. In all statistical analysis, only p-value $\leq 0.05$ was considered significant.

\section{RESULTS}

The findings of the morphometric analysis revealed that the mean diameter of pancreatic acini and islets was $26.29 \pm 4.37$ and $123.66 \pm 22.08$ in the control group, respectively (Table 1 , Figure 1 ). The detailed examination of both exocrine and endocrine parts of the pancreas revealed that the tissues were healthy with randomly distributed acini and islets among the parenchyma of the organs. The islets appeared lightly stained than the surrounding acinar cells and they were arranged in an anastomosing cord-like pattern. Thin layered connective tissue septa were seen running in between the pancreatic tissue dividing it into distinct lobules and were seen surrounding the blood vessels and ducts (Figure 2).

The mean value of diameter of acini was $12.70 \pm 1.20$, which has decreased significantly when compared to the control group $p$-value $=0.05$ and highly significant when compared to the treated group $C p$-value $=0.001$. The mean value of the diameter of the islet was $63.52 \pm 8.98$. The data has shown significant decrease in the diameter when compared to the control group $\mathrm{p}$ value $=0.02$ and highly significant when compared to treated group C p-value 0.0001 (Table 1). The low-dose treated tissues showed a reduction in the diameters acini. The H\&E stained sections revealed moderate shrinkage of islets while the cytoarchit-ecture remained intact (Figure 3).

The high-dose treated tissues exhibit the most damaging effects. Severe vascular congestion with dilatation and hemorrhage was observed (Figure 3). 
They had shrunken acini with irregular margins. Their diameter reduced to $10.06 \pm 0.89$, $p$-value $=<0.001$ and $<0.0001$, on comparison with control and low dose treated animals group B. Likewise, the catastrophic effects were also observed in the islets as well with significantly reduced mean diameter and loss of regular anastomosing pattern of cords (Figure 4).
The mean diameter decreased to about $10.06 \pm 0.89$ with $\mathrm{p}$-value $=<0.001$. The data showed a significant decrease in diameter as compared to control group $A$ and treated group B with a p-value $=0.001 \& 0.0001$ respectively (Table-1, Fig-4).

Table 1: Comparison of Diameter of pancreatic acini $(\mu \mathrm{m})$ and islets $(\mu \mathrm{m})$ of Langerhans in different Groups of Albino Rats

\begin{tabular}{cccc}
\hline $\begin{array}{c}\text { Groups } \\
(\mathbf{n = 1 0})\end{array}$ & $\begin{array}{c}\text { Treatment } \\
\text { Received }\end{array}$ & $\begin{array}{c}\text { Diameter of pancreatic } \\
\text { acini }(\mu \mathrm{m})\end{array}$ & $\begin{array}{c}\text { Diameter of pancreatic } \\
\text { islets }(\mu \mathrm{m})\end{array}$ \\
\hline $\mathrm{A}$ & Control & $26.29 \pm 4.37$ & $123.66 \pm 22.08$ \\
\hline $\mathrm{B}$ & Treated - low dose & $12.70 \pm 1.20$ & $63.52 \pm 8.98$ \\
\hline $\mathrm{C}$ & Treated - high dose & $10.06 \pm 0.89$ & $44.58 \pm 7.66$ \\
\hline Statistical Comparison within groups & & $0.02^{*}$ \\
\hline & Group B and A & $0.05^{*}$ & $<0.001^{* *}$ \\
\hline Group C and A & $<0.001^{* *}$ & $<0.001^{* *}$ \\
\hline
\end{tabular}

$*=p$-value $\leq 0.05$
$* *=p$-value $\leq 0.001$

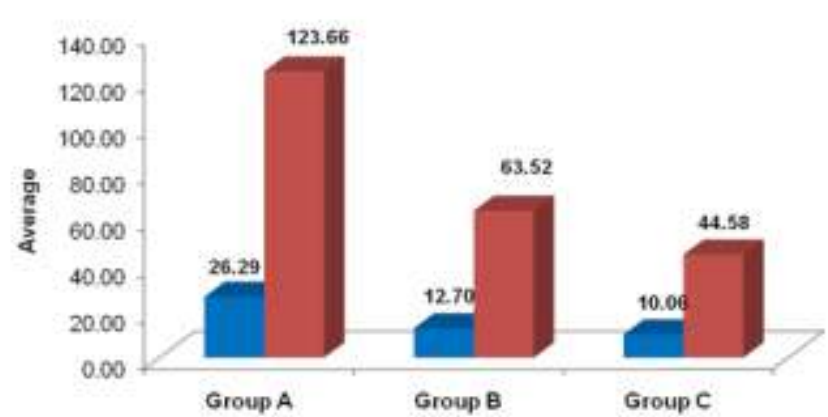

$=$ Diameter of pancreatic acini $\quad=$ Diameter of pancreatic islets

Figure 1: Comparison of Diameter of pancreatic acini $(\mu \mathrm{m})$ and islets $(\mu \mathrm{m})$ of Langerhans in different Groups of Albino Rats

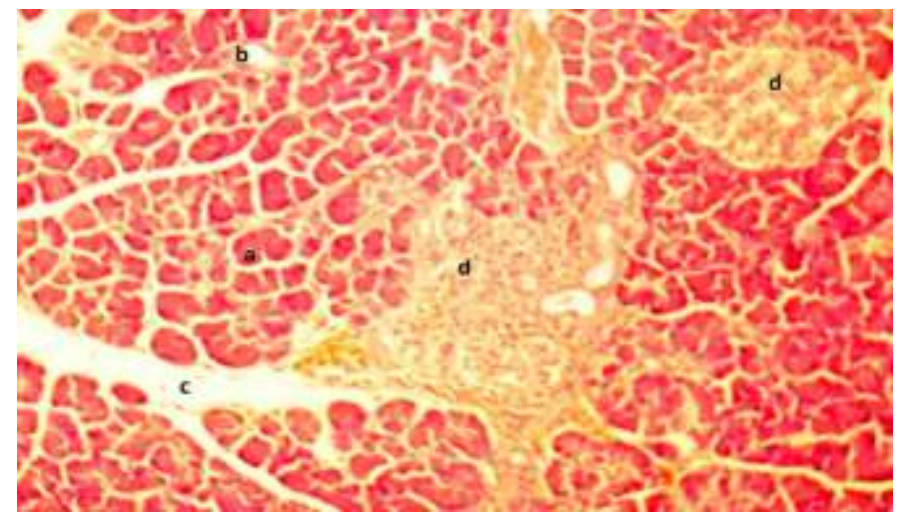

Figure 2: Control group A pancreas showing a. acini b. blood vessel c. connective tissue septa d. islet of Langerhans (H\&E 100X)

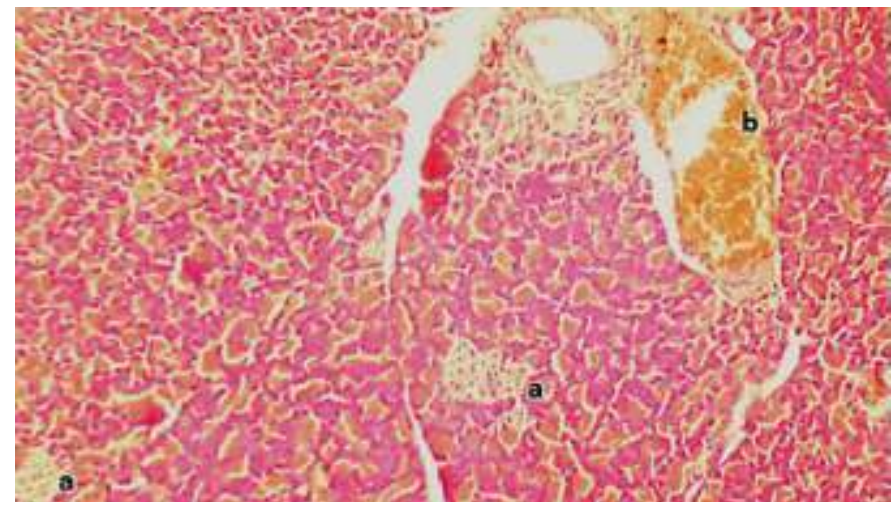

Figure 3: Treated group B showing a. shrunken islets and $b$. hemorrhagic vessel (H\&E 100X)

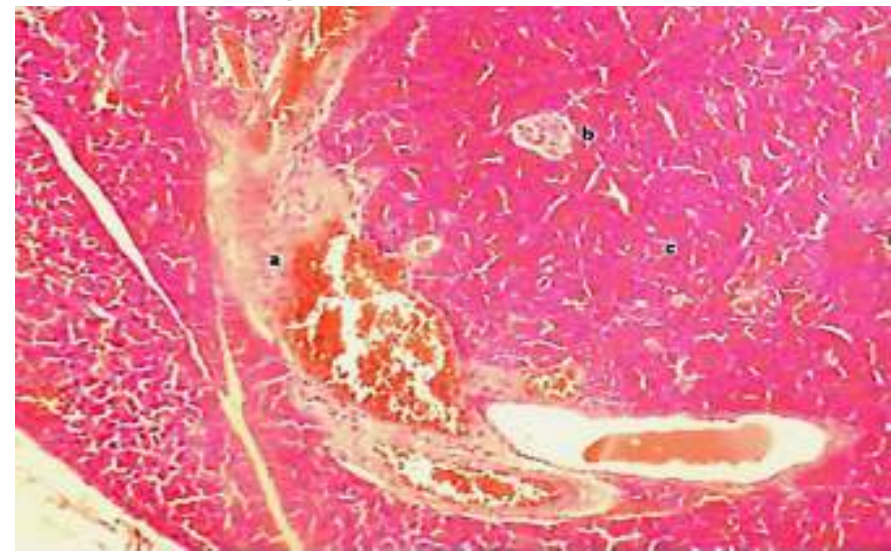

Figure 4: Treated group $C$ showing a. Dilated and congested blood vessels,

b. shrunken islet and c. distorted architecture of pancreatic acini (H\&E100X) 


\section{DISCUSSION}

The present study was aimed to observe the effects of caffeinated beverages at variable dosages on the histomorphometric parameters of the pancreas of Wistar Albino rats. For this purpose, thirty adult male Wistar Albino rats, weighing between 250-300 grams were used in the study. All the animals were randomly divided into three groups, each comprising of ten animals. One with standard laboratory diet and water ad libitum, served as control while energy drink treated at a dose of $10 \mathrm{mg} / \mathrm{kg}$ equivalent to $7.5 \mathrm{ml} /$ day and a dose of $20 \mathrm{mg} / \mathrm{kg}$ equivalent to $15 \mathrm{ml} /$ day were other two groups. This drink had a composition of caffeine, taurine, and sugar. The diameter of acini and islets of Langerhan's were the main foci of the current study. It is observed that gradual shrinkage in the diameters of both pancreatic acini and Langerhan's cells was a distinguished finding in the current study. The high dose treated animals showed a significant reduction in the diameter of both acini and islets as compared to the control group's animals. Marked vascular congestion with hemorrhage, mononuclear cell infiltration and edema were found on microscopic examination. These results are following the conclusion given by Shuaib (2019), who found a significant reduction in the diameter of neurons with pyknotic nuclei and inflammatory infiltrates while investigating the harmful effects of energy drinks on the hippocampus of rats." Furtermore, Ayuob and ElBeshbeishy have reported that energy drinks, when consumed in exaggerated amount, are responsible for inducing a pro-oxidant environment associated with an increase in protein oxidation. Various organs of the body, including the pancreas, can suffer from the resultant oxidative stress. ${ }^{9,12}$

It is reported that the consumption of energy drinks has increased drastically in the last two decades. ${ }^{13}$ The advertisements of differently labeled energy-boosting beverages on both electronic and social media make the consumers access the products. The growth of peer networking in young adults elicits the affinity-based recommendations. The target population is mostly young males and the products are associated with their sports and risk-taking activities primarily. ${ }^{14} T$ These drinks are a composition of caffeine, sugar, vitamin B derivatives, taurine, ginseng, and glucoronolactone. Other than caffeine and sugar, the adversities caused by the various components are still debatable. But the amount of caffeine and carbohydrate in these drinks are enough to cause multiple untoward effects on health. Literature has revealed the caffeine intoxication following the drink's consumption. Most of the drinks lack the consumer demographics, making the children and young adults more susceptible to caffeine intoxication since they are not tolerant of its intake. ${ }^{15}$

Similar to our study findings, Rehman et al, have described that the pancreas is an organ with narrow regeneration potential. This organ also suffers from the toxic effects of energy drinks. These beverages disrupt the normal cytoarchitecture of the gland with alteration in its functional capability. The long-drawn effects of inflammatory mediators produce deleterious consequences on both the exocrine and endocrine parts of the organ. ${ }^{16}$ Current study also finds the similar deleterious effects resulting in the damage to the parenchyma of the organ characterized by distortion of the regular connective tissue architecture, dilated and congested blood vessels and shrinkage of the internal structures of the endocrine and exocrine part of the organ. Therefore, it can be stated that prolonged exposure of the organ to any inflammatory mediator cannot be sustained by its parenchyma and can consequently lead to fibrosis. ${ }^{17}$

According to current study findings, the low dose of treated animals revealed less shrinkage when compared to the control groups. Chulia et al, has given a possible explanation of the damaging effects of energy drink treated cells when they studied the toxic effects of these beverages on human neuronal tissues and found significant damage to the cells along with loss of their enzymatic activity. They have stated that the free radical injury produced by the reactive oxygen species is mainly responsible for reacting with various cellular apparatus. Resultantly, the cells exhibit clear signs of apoptosis, including shrinkage in the size of the cell and blebbing of the cell membrane, depicting oxidativestress related injury. ${ }^{18}$ Apart from the adverse effects of many different ingredients of energy drinks on various organs and systems of the body, caffeine is found to be the most toxic one. The untoward effects have been seen on the liver and kidneys with significant alterations in the hepatic and renal profiles. ${ }^{19}$ Chronic heavy consumption of these drinks especially in teenagers' results in poor sleep, disturbed performance in school, frequent headaches, and depressive symptoms. They consume it to increase athletic performance, which enhances their thrill-seeking behavior as well. ${ }^{20}$

This study has demonstrated that the usage of energy drinks has damage the regular structure of the pancreas. Therefore, preventive measures should be disseminated especially among the vulnerable population. 


\section{CONCLUSION}

The consumption of caffeinated beverages can cause considerable harm to the regular morphology of both the exocrine and endocrine parts of the pancreas. Excessive intake of these drinks should be regulated and strictly monitored. The outcomes of the present study can be taken into consideration for further researches in the future.

ETHICAL APPROVAL: The study was approved by the Basic Medical Science Institute, JPMC Karachi.

AUTHORS' CONTRIBUTION: FR: Conception of the idea, principal investigation. ZI: Final approval of the article to be published. SH: Critical analysis of the content. LF: Drafting of the article. SR: Inter petition of the data for work. SK: Data analysis.

CONFLICT OF INTEREST: The authors have declared that no conflict of interest exists.

FUNDING: None

Received: July 02, 2020

Accepted: October 22,2020

\section{REFERENCES}

1. Terry-McElrath YM, O'Malley PM, Johnston LD. Energy drinks, soft drinks, and substance use among United States secondary school students. J Addict Med 2014; 8:6-13. doi:10.1097/01.ADM.0000435322.07020.53

2. Kemps E, Tiggemann M, Cibich M, Cabala A. Cognitive bias modification for energy drink cues. PLoS One 2019; 14:e0226387. doi:10.1371/journal.pone.0226387

3. Nehlig A, Daval JL, Debry G. Caffeine and the central nervous system: mechanisms of action, biochemical, metabolic and psychostimulant effects. Brain Res Brain Res Rev 1992;17:139-70.10.1016/0165-0173(92)90012-b.

4. Del Coso J, Munoz-Fernández VE, Munoz G, FernandezElías VE, Ortega JF, Hamouti N, Barbero JC, MuñozGuerra J. Effects of a caffeine-containing energy drink on simulated soccer performance. PLoS One 2012; 7:e31380. doi: 10.1371/journal.pone.0031380

5. Somers KR, Svatikova A. Cardiovascular and Autonomic Responses to Energy Drinks-Clinical Implications. J Clin Med 2020; 9:431. doi:10.3390/jem9020431

6. Curran CP, Marczinski CA. Taurine, caffeine, and energy drinks: Reviewing the risks to the adolescent brain. Birth Defects Res 2017; 109:1640-8.

doi: $10.1002 / b d r 2.1177$

7. Junyent F, Utrera J, Romero R, Pallàs M, Camins A, Duque $D$, Auladell $C$. Prevention of epilepsy by taurine treatments in mice experimental model. J Neurosci Res 2009; 87:1500-8. doi: 10.1002/jnr.21950

8. Kuwabara H, Yamasue H, Koike S, Inoue H, Kawakubo Y,
Kuroda $M$, et al. Altered metabolites in the plasma of autism spectrum disorder: a capillary electrophoresis time-of-flight mass spectroscopy study. PLoS One 2013; 8:e73814. doi:10.1371/journal.pone.0073814

9. Ayuob N, ElBeshbeishy R. Impact of an Energy Drink on the Structure of Stomach and Pancreas of Albino Rat: Can Omega-3 Provide a Protection? PLoS One 2016; 11:e0149191. doi:10.1371/journal.pone.0149191

10. Shahriah S, Nurunnabi AS, Begum GN, Kabir R. Histomorphometric changes of pancreatic islets with advancing age - A postmortem study in a Bangladeshi male population. Nepal J Med Sci 2014; 3:63-7. doi: 10.3126/njms.v3i1.10361

11. Shuaib DM. Effect of energy drinks on rat hippocampus and the possible neuroprotective role of sesame oil: a histological, immunohistochemical, and molecular study. Med J Cairo Univ 2019; 87:3871-3881.

doi: $10.21608 / \mathrm{mjcu} .2019 .70139$

12. Valle MT, Couto-Pereira NS, Lampert C, Arcego DM, Toniazzo AP, Limberger RP, Et al. Energy drinks and their component modulate attention, memory, and antioxidant defences in rats. Eur J Nutr 2018; 57:2501-11. doi: $10.1007 /$ s00394-017-1522-z

13. Alsunni A A. Are energy drinks physiological ? Pak J Physiol 2011; 7: 44-9.

14. Emond JA, Sargent JD, Gilbert-Diamond D. Patterns of energy drink advertising over US television networks. J Nutr Educ Behav 2015; 47:120-6.e1.

doi: 10.1016/j.jneb.2014.11.005

15. Reissig CJ, Strain EC, Griffiths RR. Caffeinated energy drinks-a growing problem. Drug Alcohol Depend 2009; 99:1-10. doi:10.1016/j.drugalcdep.2008.08.001.

16. Rehman F, Islam Z, Hameed U, Rehman S. The effect of energy drinks on the pancreas of Wistar Albino rats- $A$ microscopic study. Pak Armed Forces Med J 2020; 70:524-8.

17. Tandon RK, Garg PK. Oxidative stress in chronic pancreatitis: pathophysiological relevance and management. Antioxid Redox Signal 2011; 15:2757-66. doi: 10.1089 /ars.2011.4115

18. Zeidan-Chulia F, Gelain DP, Kolling EA, Rybarczyk-Filho JL, Ambrosi P, Terra SR, et al. Major components of energy drinks (caffeine, taurine, and guarana) exert cytotoxic effects on human neuronal SH-SY5Y cells by decreasing reactive oxygen species production. Oxid Med Cell Longev 2013;2013:791795. doi:10.1155/2013/791795

19. Al Yacoub R, Luczkiewicz D, Kerr C. Acute kidney injury and hepatitis associated with energy drink consumption: a case report. J Med Case Rep 2020;14:23. doi: 10.1186/s13256-019-2340-0

20. Troxel WM, Tucker JS, Ewing B, Miles JN, D'Amico EJ. Sleepy teens and energy drink use: results from an ethnically diverse sample of youth. Behav Sleep Med 2018; 16:223-34. doi: 10.1080/15402002.2016.1188390 